NASA Technical Memorandum 107021

\title{
Low-Temperature Operation of a Buck DC/DC Converter
}

Biswajit Ray

Lewis Research Center

Cleveland, Ohio

Scott S. Gerber

NYMA, Inc.

Brook Park, Ohio

Richard L. Patterson and Ira T. Myers

Lewis Research Center

Cleveland, Ohio

Prepared for the

Applied Power Electronics Conference and Exposition cosponsored by the IEEE Power Electronics and Industry Applications Societies and the Power Sources Manufacturers Association Dallas, Texas, March 5-9, 1995

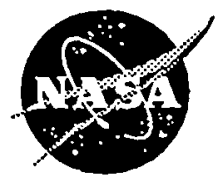

National Aeronautics and Space Administration

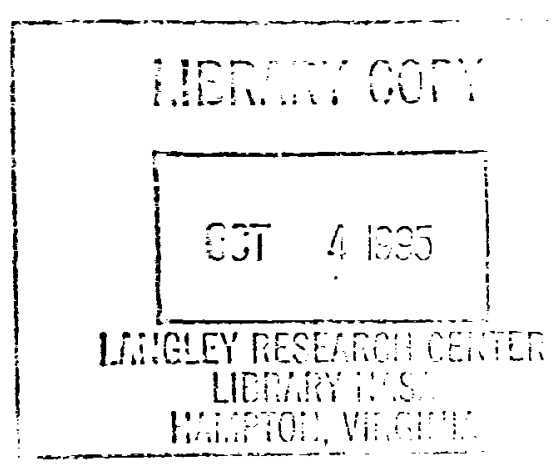



.

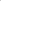




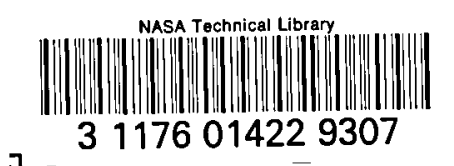

\section{LOW-TEMPERATURE OPERATION OF A BUCK DC/DC CONVERTER}

\author{
Biswajit Ray ${ }^{1}$ \\ NRCANASA Lewis \\ MS: 301-1 \\ 21000 Brookpark Road \\ Cleveland, OH 44135
}

\author{
Scott S. Gerber \\ Nyma, Inc. \\ MS: $301-1$ \\ 2001 Aerospace Parkway \\ Brook Park, OH 44142
}

\author{
Richard L. Patterson Ira T. Myers \\ NASA Lewis Research Center \\ MS: $301-2$ \\ 21000 Brookpark Road \\ Cleveland, OH 44135
}

\begin{abstract}
Low-temperature $\left(77^{\circ} \mathrm{K}\right)$ operation of a $42 / 28 \mathrm{~V}, 175$ W, $50 \mathrm{kHz}$ PWM Buck dc/dc converter designed with commercially available components is reported. Overall, the converter losses decreased at $77^{\circ} \mathrm{K}$ compared to room temperature operation. A full-load efficiency of $97 \%$ was recorded at liquid-nitrogen temperature, compared to $95.8 \%$ at room temperature. Power MOSFET operation improved significantly where as the output rectifier operation deteriorated at low-temperature. The performance of the output filter inductor and capacitor did not change significantly at $77^{\circ} \mathrm{K}$ compared to room temperature performance. It is possible to achieve highdensity and high efficiency power conversion at low-temperatures due to improved electronic, electrical and thermal properties of materials.
\end{abstract}

\section{Introduction}

Low-temperature signal level electronics in use or contemplated, range from single-transistor amplifiers to computer systems employing many VLSI integrated circuits. Recent advances in high-temperature $\left(125^{\circ} \mathrm{K}\right)$ superconductor technology have also motivated the investigation of power electronic devices, circuits, and systems at low temperatures. Low-temperature electronics will interface the superconducting electronics and roomtemperature electronics. In general, low-temperature electronics $\left(77^{\circ} \mathrm{K}\right)$ will find applications where: (1) the ambient includes low-temperatures such as in deep-space, (2) a low-temperature environment is already present, such as in magnetic resonance imaging systems, and (3) the performance enhancement of existing room-temperature technology is of importance. In the future, low-temperature power electronics (LTPE) will find applications in MagLev transportation, high-power motor drive systems, and power supplies for high-speed supercomputers. An important aerospace application of LTPE is deep-space exploration. As shown in Fig. 1, the ambient temperature of a space probe is on the order of $40^{\circ} \mathrm{K}$ in deep-space. The electronics will thus have to operate reliably over a wide temperature range which includes the low-temperature region. Currently, radio-isotope heating units (RHU) are used to keep electronics warm for deep-space probes. However, an additional heat-rejection system is needed to reject the excess heat when the probe is near the earth orbit since RHUs operate continuously. Electronics that will operate reliably in a wide temperature range including the lowtemperature region will certainly find applications in future space probes.

The operation of power semiconductor devices at low temperatures is expected to result in an improved power handling capability due to increased carrier mobility, improved reliability due to lower junction temperatures, and higher power density due to better thermal conductivity of packaging materials and silicon. To investigate the overall circuit performance at $\mathrm{LN}_{2}$ temperature, a $42 \mathrm{~V} \pm 20 \% / 28 \mathrm{~V}$, $175 \mathrm{~W}, 50 \mathrm{kHz}$ pulse-width modulated (PWM) buck dc/dc converter was designed, fabricated, and tested at room temperature $\left(300^{\circ} \mathrm{K}\right)$, as well as at liquid nitrogen $\left(\mathrm{LN}_{2}\right)$ temperature $\left(77^{\circ} \mathrm{K}\right)$. At the component level, the inductor losses as well as the switching and conduction behavior of a power MOSFET and diode were also studied.

\section{PWM Buck DC/DC Converter}

A $42 \mathrm{~V} \pm 20 \% / 28 \mathrm{~V}, 175 \mathrm{~W}, 50 \mathrm{kHz}$ PWM buck $\mathrm{dc} / \mathrm{dc}$ converter was designed and operated at room temperature (RT) as well as at liquid nitrogen temperature (LNT). This type of converter can potentially be used in small scientific/experimental spacecraft such as the proposed CLIR (Combined Lander and Instrumented Rover). The converter circuit is shown in Fig. 2, and it is designed for a minimum output power of $35 \mathrm{~W}$ and a maximum output voltage ripple of $0.5 \%$.

Based on the steady-state analysis for continuous conduction mode of operation [1], the following design equations are used for the power circuit design:

$$
\begin{aligned}
& L_{f} \geq \frac{V_{o}\left(1-D_{\min }\right) T_{s}}{2 I_{o, \min }} \\
& C_{f} \geq \frac{\left(1-D_{\min }\right) V_{o}}{8 f_{s}^{2} \Delta V_{o}}
\end{aligned}
$$

\footnotetext{
${ }^{1}$ This work was performed while the first author held a National Research Council-NASA Lewis Research Associateship, on leave from the University of Puerto Rico-Mayaguez Campus.
} 
where, $D_{\min }=$ minimum duty-ratio $=V V_{i n, \max }, I_{o, \min }=$ minimum output (load) current for continuous conduction mode of operation, $f_{s}=$ switching frequency $=I / T_{s}$, and $\Delta V_{0}$ $=$ peak-to-peak output ripple voltage.

Based on equation (1), the required output filter inductor of $100 \mu \mathrm{H}$ was designed using a molypermalloy powder (MPP) core. Silver-plated copper wire with teflon resin tape insulation suitable for wide-temperature operation was used for winding the inductor. The MPP core was expected to operate at LNT with a somewhat increased loss [2,3]. An output filter capacitance of $60 \mu \mathrm{F}$ was used instead of the calculated value of $45 \mu \mathrm{F}$ from equation (2), to provide a design margin for the output ripple voltage against the drop in capacitor value at low temperatures. Standard low ESR metalized polypropylene film capacitors were used because of their superior low-temperature characteristics.

Power semiconductor selection: For low temperatures, the primary semiconductor material is $\mathrm{Si}$, although $\mathrm{GaAs}$ also has considerable potential and the primary device is the field-effect transistor in various forms [4]. Reduced temperature operation offers improvements in performance through improvement of materials-based properties such as electronic carrier mobility, thermal conductivity, and electrical conductivity. Substantial improvements in reliability are also expected since degradation mechanisms are thermally activated. Therefore, LNT operation of Sibased power semiconductors is of great interest for achieving high efficiency converters.

For this work, an IRFP 250 power MOSFET (33 A, $200 \mathrm{~V}, 85 \mathrm{~m} \Omega, 650 \mathrm{pF}$ device) is used as the primary switch and a MUR 3020PT ultrafast diode $(2 * 15 \mathrm{~A}, 200 \mathrm{~V})$ as the output rectifier. Both devices have a TO-3P plastic package.

\section{Experimental Procedure}

The experimental setup is shown in Fig. 3. The control circuitry was kept at room temperature while the power circuitry was placed in a Dewar flask. Data were recorded for full-load ( $175 \mathrm{~W}$ of output power) operation both at room and $\mathrm{LN}_{2}$ temperature using the same circuit layout. For LNT data, the Dewar flask was first filled with $\mathrm{LN}_{2}$ and then the power circuit board was dipped while the converter was powered on. The converter was operated continuously for one hour before recording each set of data. An R-C snubber across the power MOSFET was used to reduce the switching transients. The snubber consisted of a $50 \Omega$ resistor in series with a $0.002 \mu \mathrm{F}$ capacitor. Data were recorded with and without the snubber to study the switching performance of the semiconductor devices at low temperature. Some of the recorded waveforms are shown in
Figs. 4-11 and are discussed in the following section. The control circuitry as well as all measuring and sensing instruments were at room temperature while the power circuitry was in the $\mathrm{LN}_{2}$ Dewar, resulting in a non-compact circuit layout. The power converter was able to restart at $77^{\circ} \mathrm{K}$.

\section{Discussion of Results}

The recorded circuit efficiency is shown in Table I. Efficiency improved by about $1.5 \%$ due to the use of a snubber both at RT as well as LNT while reducing unwanted high frequency ringing between circuit inductance and MOSFET junction capacitance as can be seen in Figs. 4-7. More interestingly, the circuit efficiency improved by about $1.3 \%$ at $\mathrm{LN}_{2}$ temperature with or without the snubber circuit. An efficiency of $97 \%$ was recorded for LNT operation with a snubber circuit.

\begin{tabular}{|l|l|l|}
\hline \multicolumn{3}{|c|}{$\begin{array}{c}\text { Table I } \\
\text { of PWM Buck DC/DC Conved }\end{array}$} \\
\hline $\begin{array}{l}\text { Room } \\
\text { temperature } \\
\text { operation }\end{array}$ & $\begin{array}{l}\text { Liquid-nitrogen } \\
\text { temperature } \\
\text { operation }\end{array}$ & $\begin{array}{l}\text { R-C snubber } \\
\text { connected }\end{array}$ \\
\hline $94.2 \%$ & $95.5 \%$ & No \\
\hline $95.8 \%$ & $97.0 \%$ & Yes \\
\hline
\end{tabular}

At LNT, the diode loss almost doubled compared to RT operation due to increased forward voltage drop. The reverse saturation current of a p-n junction is proportional to the square of the intrinsic carrier density, which decreases by approximately 30 orders of magnitude between RT and LNT. The large reduction in saturation current is accompanied by an increase in the forward bias voltage needed to reach a given level of conduction in the forward direction. However, the reverse recovery peak current and time of diode rectifier improved significantly at lowtemperature.

The conduction loss of the power MOSFET decreased significantly at LNT due to reduction in drain-tosource resistance. The primary reason for this improvement is the increased mobility of carriers due to reduced scattering. Carrier freezeout is not a problem for the enhancement mode MOSFETs since the source-drain regions are heavily doped. The turn-on loss of the switch $\left(0.5 \mathrm{CV}^{2}\right)$ also reduced at LNT due to decreased value of the drain-to-source junction capacitance [5] as can be seen in Figs. 8 and 9. There is a significant turn-off loss $\left(0.5 \mathrm{LI}^{2}\right)$ due to resonance between the circuit layout inductance and MOSFET junction capacitance as can be seen in Figs. 4 and 5. However, $\mathrm{LN}_{2}$ operation did reduce the turn-off loss a little. As can be seen in Figs. 10 and 11, the frequency of oscillation at turn-off increased at LNT because of slightly 
reduced value of MOSFET junction capacitance. This situation can be improved significantly by having a compact circuit layout which was not possible in this case because the power circuit was dipped in $\mathrm{LN}_{2}$ whereas the control circuitry was at room temperature. Also, all the measurements were taken outside the Dewar.

The best way to attack this problem is to use a resonant (soft) switching technique instead of a PWM (hard) switching topology. Such a circuit employing zero-voltage switching for both switches is shown in Fig. 12. Ultra-high efficiency can be achieved from this type of circuit at LNT because the switching loss will be practically eliminated, and the conduction loss, which is significant at room temperature, is reduced dramatically due to very low drainto-source on-resistance at LNT $[6,7]$.

The conduction loss of MOSFET decreases whereas that of the diode rectifier increases at low-temperature, making synchronous rectification highly attractive for lowtemperature power converters as shown in Fig. 13. Another interesting finding was that the power MOSFETs rise and fall times improved marginally at LNT, unlike in signal MOSFETs, where the speed of operation improved by almost a factor of two [4]. This finding supports the results reported in [8].

The MPP inductor loss was expected to increase slightly at LNT due to increased flux-density and decreased core resistivity [9]. However, measurements indicate that the loss practically remained unchanged. Further study of low-temperature magnetics is needed to understand the temperature dependence of hysteresis and eddy current losses, and other magnetic properties. The output filter capacitor used is film type and its value is expected to drop slightly at LNT [6], however, it was not studied in this work. The increased thermal conductivity of the capacitor body will in effect increase its current capability as will the voltage capability of the insulating film.

In terms of reliability, many degrading mechanisms are thermally activated and they follow an Arthenius-like equation for the mean-time-between-failure $(M T B F)$ or lifetime given by,

$M T B F \propto e^{E_{\lambda} / k T}$

where, $E_{A}$ is an activation energy for electromigration, interdiffusion, chemical reaction, or corrosion and is in the range of 0.4 to $1.0 \mathrm{eV}$ for these processes, $k$ is Boltzmann's constant, and $\mathrm{T}$ is temperature in ${ }^{\circ} \mathrm{K}$. Therefore, as the temperature is reduced, there is an exponential increase in lifetime. However, this theoretical justification has not been yet supported experimentally. Thermal cycling is another important unexplored area.

\section{Future Work}

In this work, only the power components were dipped in $\mathrm{LN}_{2}$, whereas the control circuit was at room temperature. However, performance of the converter can be further improved if the control circuit can also be operated in $\mathrm{LN}_{2}$, making it possible to design compact power converters. Currently, the design of power control circuits using commercially available CMOS and BiCMOS integrated circuits is being carried out. The operation of integrated circuits at cryogenic temperatures will result in increased speed, reduced latch-up susceptibility, reduced leakage current, and reduced thermal noise. The variation of switching frequency and its effect on the power converter performance will have to be investigated.

\section{Conclusions}

This work demonstrates that it is possible to design and operate power converters efficiently at low-temperatures with commercially available components. The PWM buck converter efficiency improved by $1.2 \%$ at liquid-nitrogen temperature compared to room temperature operation. Performance of power MOSFET improves significantly and that of rectifier detoriates at low temperatures, making synchronous rectification highly attractive. Passive components loss did not change significantly with decreasing temperatures. Ultra-high efficiency power conversion is possible using resonant circuits at lowtemperatures. Research must continue to exploit the lowtemperature characteristics of signal and power level active and passive components in improving the overall power system performance.

\section{References}

1. N. Mohan, T. M. Undeland, and W. P. Robbins, "Power electronics: converters, applications and design," pp. 66-74, John Wiley, 1989.

2. "Tape wound cores - design manual," TWC-400, Magnetic, Inc., 1992.

3. F. W. Ackermann, et. al., "Magnetic properties of commercial soft magnetic alloys at cryogenic temperatures," Adv. Cryogenic Engrg., Vol. 16, pp. 46-50, Plenum Press, 1971.

4. R. K. Kirschman, “Cold electronics: an overview," Cryogenios, Vol. 25, No. 3, pp. 11S-122, Mar. 1985.

5. R Singh and B. J. Baliga, “Analysis and optimization of power MOSFETs for cryogenic operation," Solid State Electronias, Vol. 36, No. 8, pp. 1203$1211,1993$.

6. R. Blanchard and R. Severns, "Designing switched-mode power converters for very low temperature operation," Proc. Powercon 10, pp. D-2.1-D-2.11, 1983.

7. O. M. Mueller and K. G. Herd, "Ultra-high efficiency power conversion using cryogenic MOSFETs and HT-superconductors," IEEE PESC rec., pp. 772-778, June 1993.

8. J. L. Hudgins, S. Menhart, and W. M. Portnoy, "The low temperature switching performance of thyristors and MOSFETs," IEEE PESC Rec., pp. 429-434, June 1990.

9. J. J. Gniewek and R. L. Powell, "Temperature dependence of magnetic losses," Adv. Cryogenic Engrg., Vol. 7, pp. 303-310, Plenum Press, 1962. 


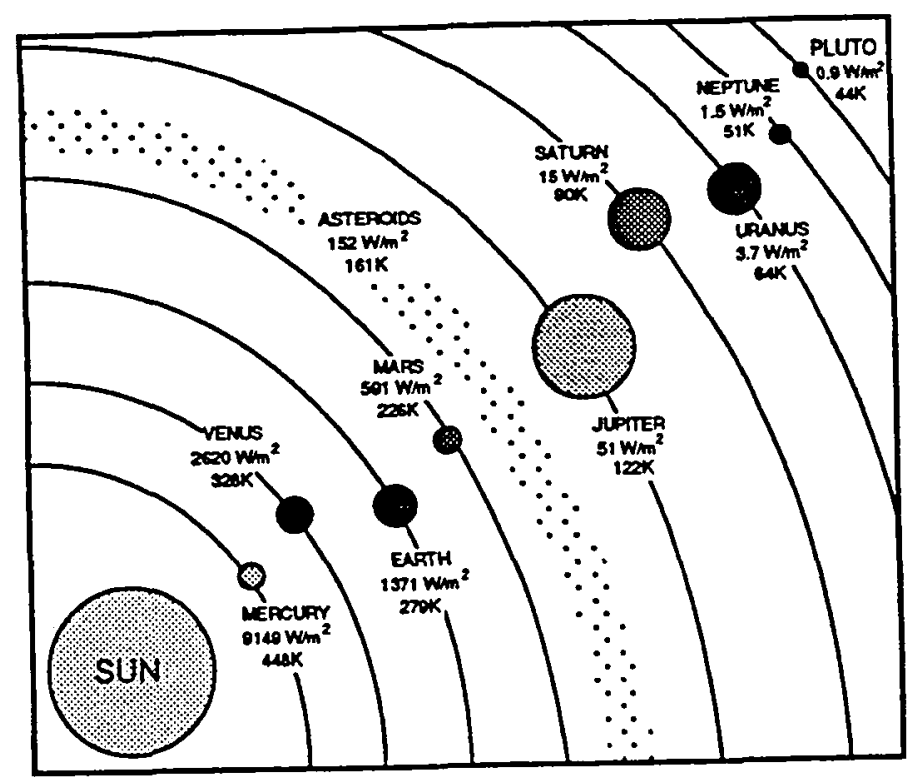

Fig 1 Solar intensity and space probe temperature.

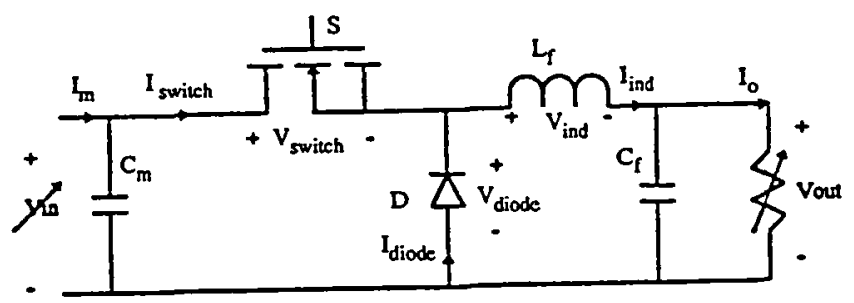

Fig 2 PWM buck DC/DC converter.

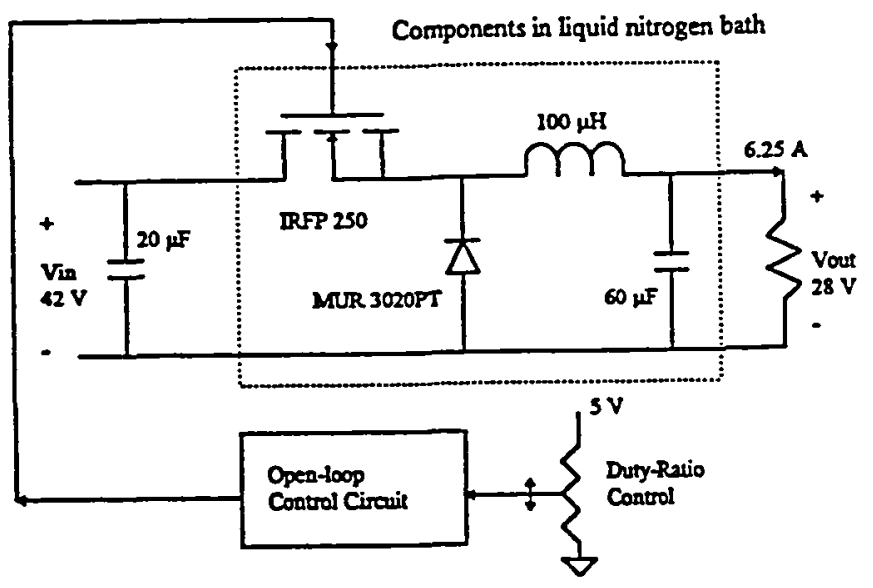

Fig. 3 Experimental setup for low-temperature testing

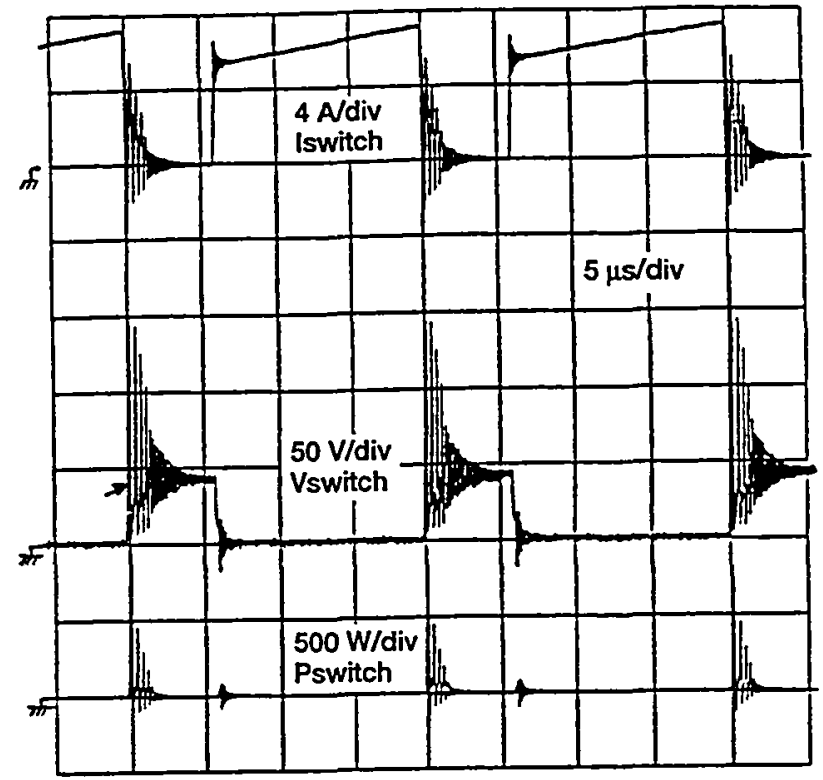

Fig. 4 Switch waveforms at room temperature. (without snubber)

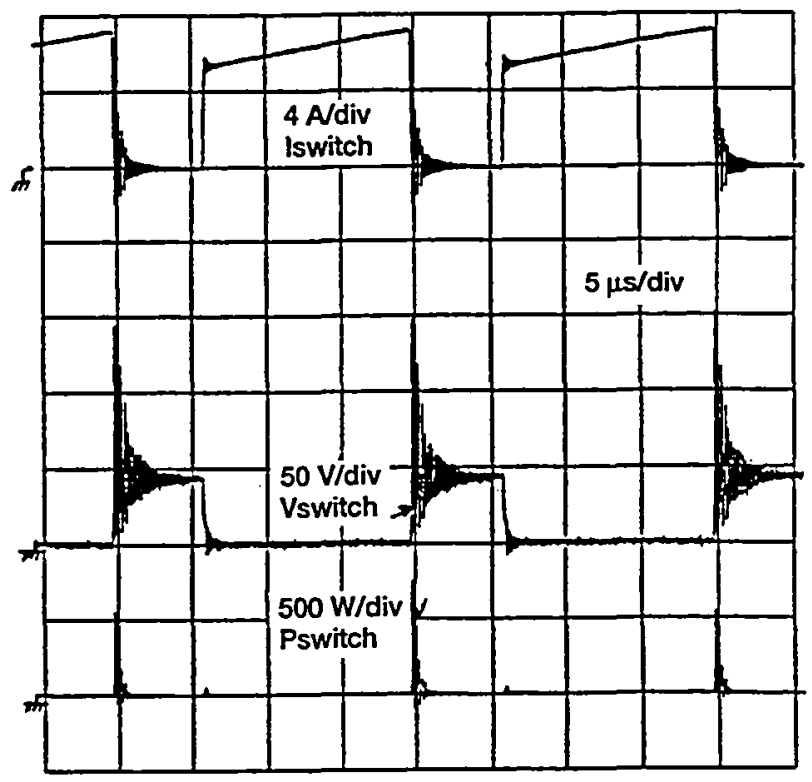

Fig 5 Switch waveforms at $\mathrm{LN}_{2}$ temperature. (without snubber) 


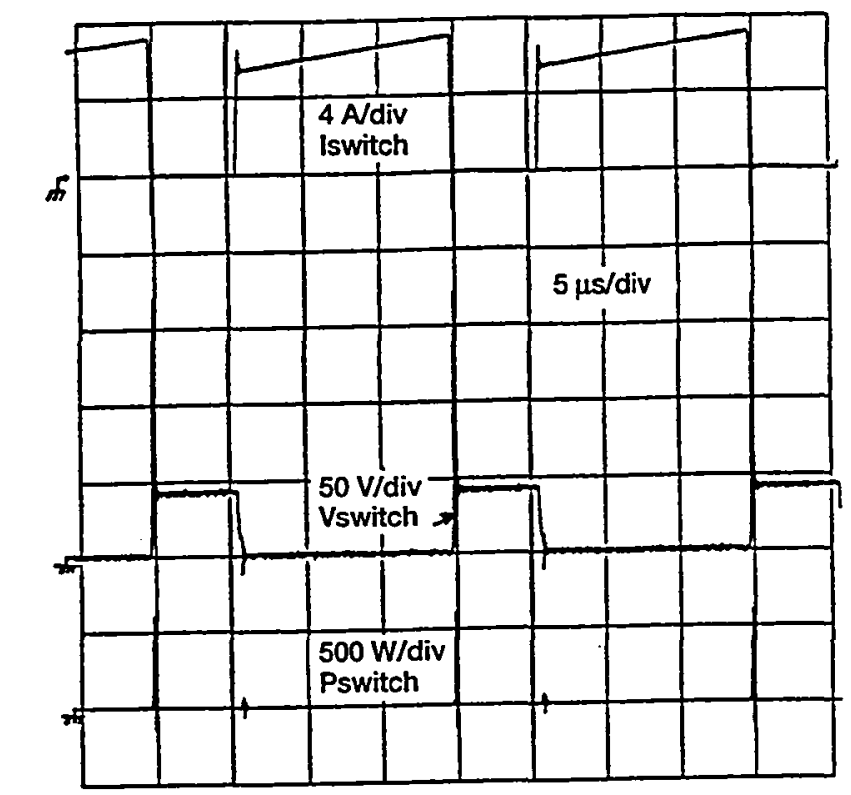

Fig. 6 Switch waveforms at room temperature. (with snubber)

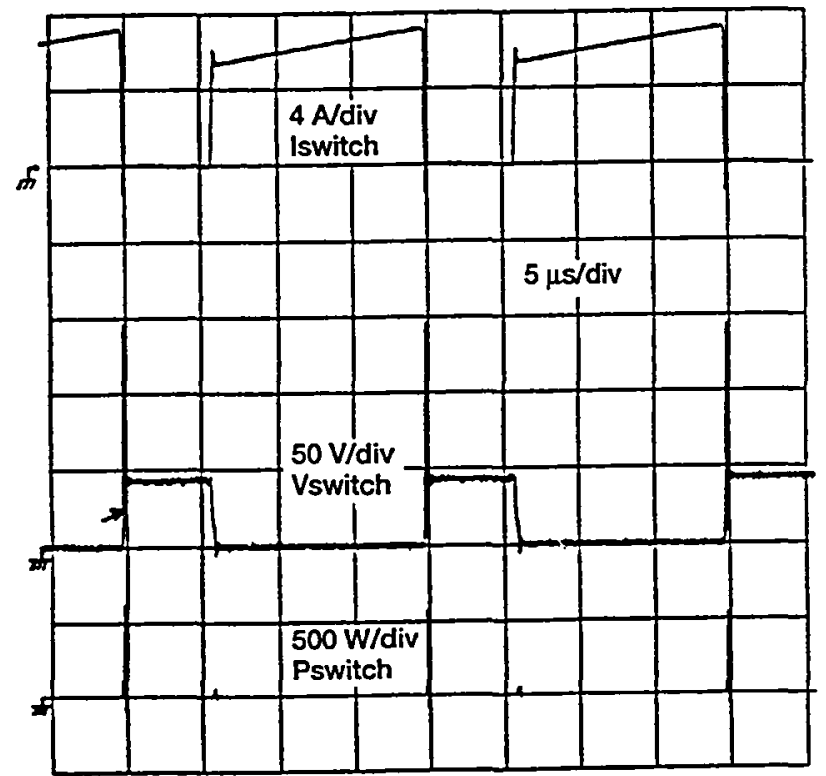

Fig 7 Switch waveforms at $\mathrm{LN}_{2}$ temperature. (with snubber)

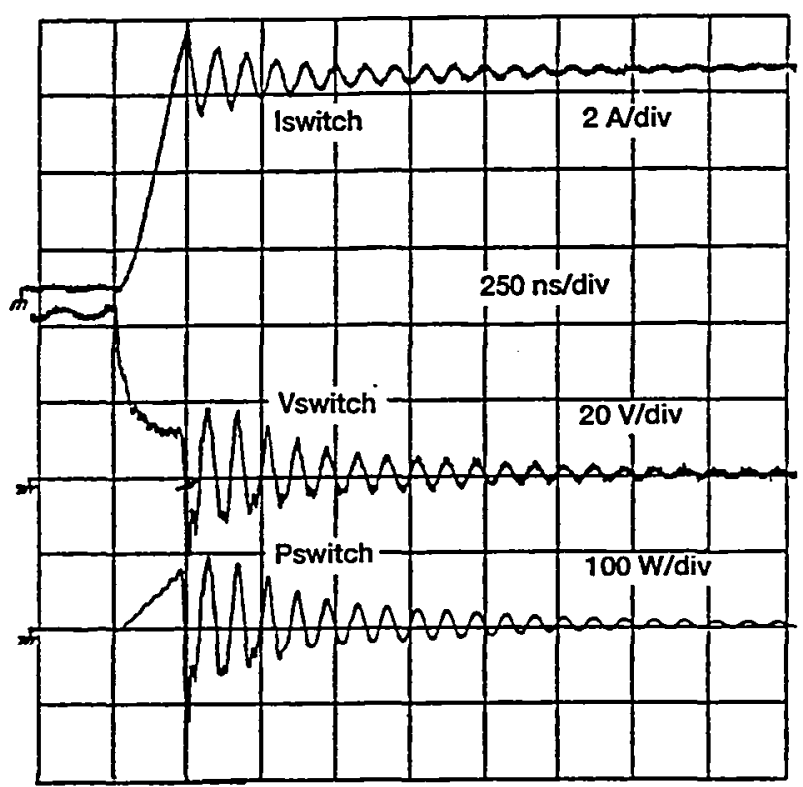

Fig. 8 Switch turn-on at room temperature. (without snubber)

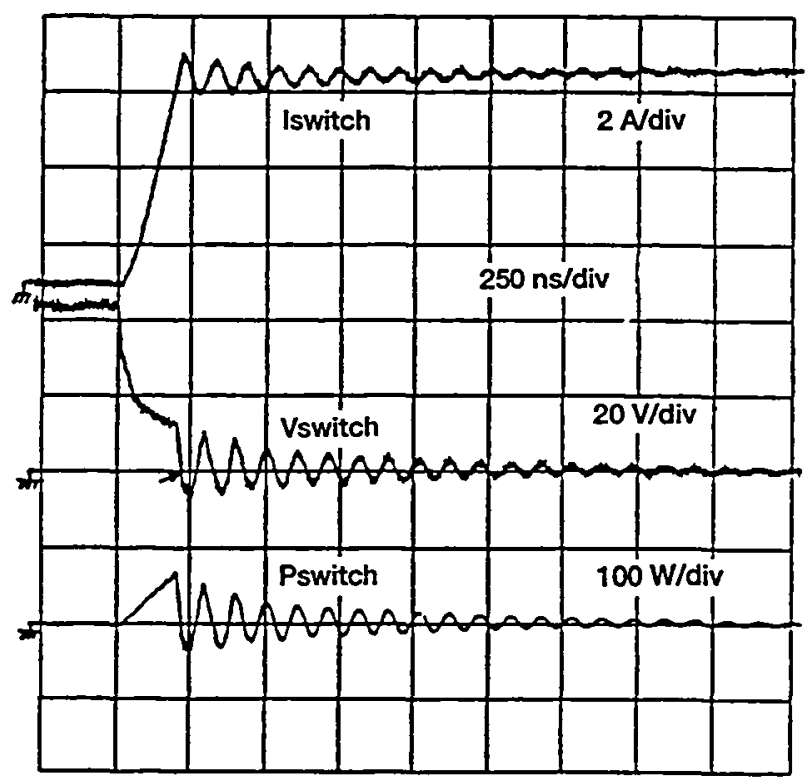

Fig 9 Switch turn-on at $\mathrm{LN}_{2}$ temperature. (without snubber) 


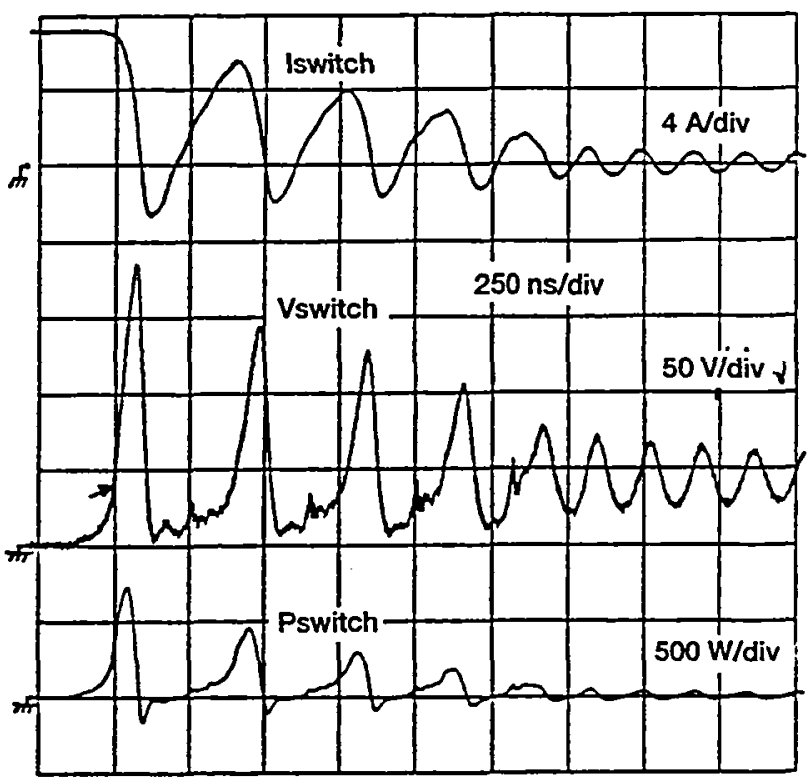

Fig 10 Switch turn-off at room temperature. (without snubber)

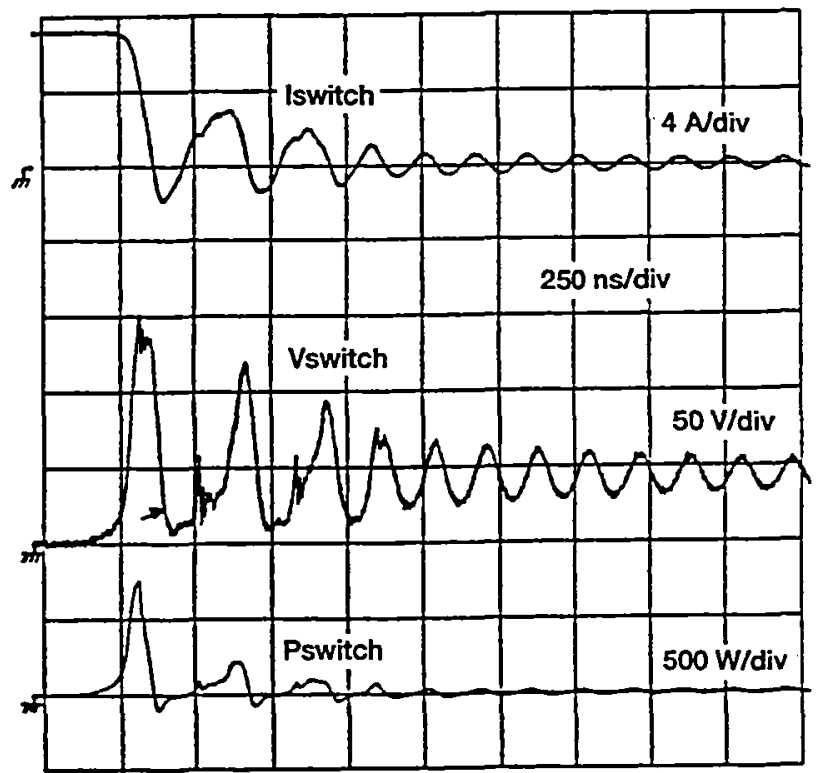

Fig. 11 Switch turn-off at $\mathrm{LN}_{2}$ temperature. (without snubber)

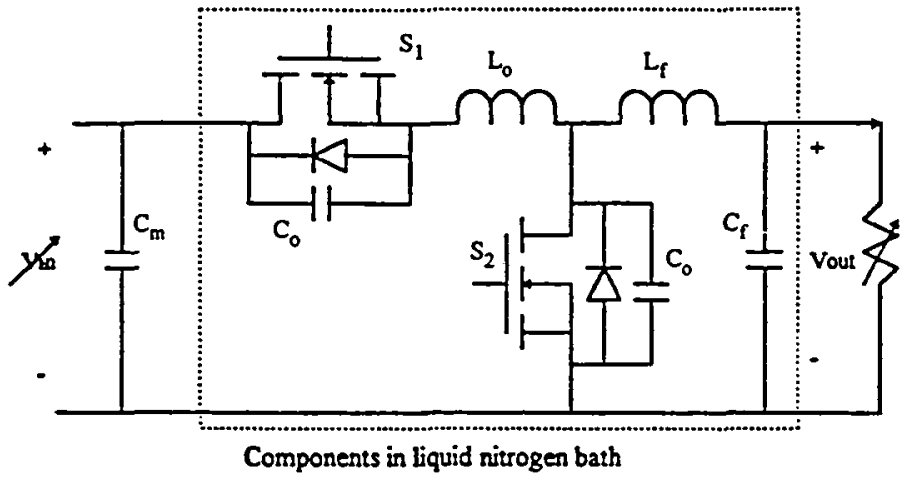

Fig. 12 Zero-voltage switching multi-resonant topology for high-efficiency power conversion at low-temperature.

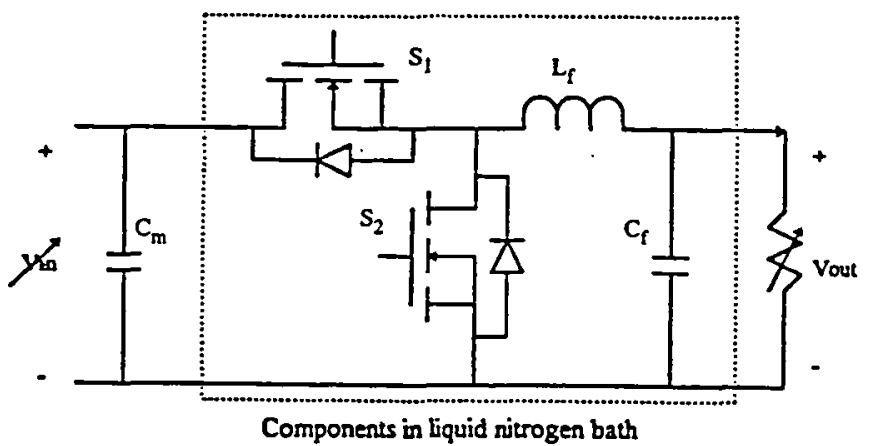

Fig. 13 Low-temperature synchronous rectification. 
Public reporting burden for this collection of information is estimated to average I hour per response, including the time tor reviewing instructions, searching existing data sources, gathering and maintaining the data needed, and completing and reviowing the colloction of information. Send comments regarding this burden estimate or any other aspect of this collection of Information, including suggestions for reducing this burden, 10 Washington Headquarters Services, Directorate for Information Operations and Reports, 1215 Jefferson Davis Highway, Suite 1204, Arlington, VA 22202-4302, and to the Office of Management and Budget, Papenwork Reduction Project (0704-0188), Washington, DC 20503.
1. AGENCY USE ONLY (Leave blank)
2. REPORT DATE
August 1995
3. REPORT TYPE AND DATES COVERED
Technical Memorandum

4. TIILE AND SUBTITLE

Low-Temperature Operation of a Buck DC/DC Converter

\section{AUTHOR(S)}

WU-233-02-0C

Biswajit Ray, Scott S. Gerber, Richard L. Patterson, and Ira T. Myers

7. PERFORMING ORGANIZATION NAME(S) AND ADDRESS(ES)

National Aeronautics and Space Administration

Lewis Research Center

Cleveland, Ohio 44135-3191

5. FUNDING NUMBERS

8. PERFORMING ORGANIZATION REPORT NUMBER

E-9343-1

9. SPONSORING/MONITORING AGENCY NAME(S) AND ADDRESS(ES)

10. SPONSORING/MONITORING AGENCY REPORT NUMBER

National Aeronautics and Space Administration

Washington, D.C. 20546-0001

NASA TM-107021

11. SUPPLEMENTARY NOTES

Prepared for the Applied Power Electronics Conference and Exposition cosponsored by the IEEE Power Electronics and Industry Applications Societies and the Power Sources Manufacturers Association, Dallas, Texas, March 5-9, 1995. Biswajit Ray, National Research Council-NASA Research Associate at Lewis Research Center, Scott S. Gerber, NYMA, Inc., 2001 Aerospace Parkway, Brook Park, Ohio 44142; Richard L. Patterson and Ira T. Myers, NASA Lewis Research Center. Responsible person, Richard L. Patterson, organization code 5430, (216) 433-8166.

12a. DISTRIBUTIONAVAILABILTTY STATEMENT 12b. DISTRIBUTION CODE

Unclassified -Unlimited

Subject Categories 20 and 33

This publication is available from the NASA Center for Aerospace Information, (301) 621-0390.

\section{ABSTRACT (Maximum 200 words)}

Low-temperature $\left(77^{\circ} \mathrm{K}\right)$ operation of a $42 / 28 \mathrm{~V}, 175 \mathrm{~W}, 50 \mathrm{kHz}$ PWM Buck dc/dc converter designed with commercially available components is reported. Overall, the converter losses decreased at $77^{\circ} \mathrm{K}$ compared to room temperature operation. A full-load efficiency of $97 \%$ was recorded at liquid-nitrogen temperature, compared to $95.8 \%$ at room temperature. Power MOSFET operation improved significantly where as the output rectifier operation deteriorated at low-temperature. The performance of the output filter inductor and capacitor did not change significantly at $77^{\circ} \mathrm{K}$ compared to room temperature performance. It is possible to achieve high-density and high efficiency power conversion at low-temperatures due to improved electronic, electrical and thermal properties of materials.

\begin{tabular}{l} 
14. SUBJECT TERMS \\
Cold electronics; Electronics; Cryogenics; Power; Low te \\
\hline $\begin{array}{l}\text { 17. SECURTY CLASSIFICATION } \\
\text { OF REPORT } \\
\text { Unclassified }\end{array}$ \\
$\begin{array}{c}\text { 18. SECURTY CLASSIFICATION } \\
\text { OF THIS PAGE } \\
\text { Unclassified }\end{array}$ \\
\hline
\end{tabular}
19. SECURITY CLASSIFICATION OF ABSTRACT Unclassified 
National Aeronautics and

Space Administration

\section{Lewis Research Center}

21000 Brookpark Rd.

Cleveland, $\mathrm{OH}$ 44135-3191

Official Business

Penalty for Private Use $\$ 300$

POSTMASTER: If Undeliverable - Do Not Return 